ИСТОРИЯ

DOI: $10.17805 /$ trudy.2017.6.5

\title{
«ТРИДЦАТЬ ЛЕТ И ТРИ ГОДА»: О ХРОНОЛОГИИ РАННЕГО СЛАВЯНСКОГО ИСТОРИОПИСАНИЯ"
}

\author{
С. В. Алексеев
}

Историко-просветительское общество «Радетель», г. Москва

Аннотация: В статье рассматривается вопрос о происхождении хронологии ранних славянских исторических сочинений: «Болгарской апокрифической летописи», первых русских летописей, «Летописи попа Дуклянина». Показывается как «подражательный» характер хронологических схем ранней истории по отношению к библейской и византийской хроникальной традиции, так и тесная их связь с фольклорными числовыми формулами. $B$ связи с этим указывается на крайнюю условность конкретных дат, в том числе содержащихся в русском летописании.

Ключевые слова: летописи; хроники; устная традиция; средневековая литература; фольклор; Болгарская апокрифическая летопись; Повесть временных лет; Летопись попа Дуклянина

\section{«THIRTY AND THREE YEARS»: ON THE CHRONOLOGY OF THE EARLY SLAVIC HISTORIOG-RAPHY}

\author{
S. V. Alekseev \\ Historical and Educational Society «Radetel», Moscow
}

\begin{abstract}
The article considers the origin of the chronology of the early Slavic historical works: "Bulgarian Apocryphal Chronicle", the first Russian annals, "The Chroni-cle of the Priest of Duklja". It shows both an "imitative" character of chronologi-cal schemes of early history in relation to the Biblical and Byzantine chronicle tra-dition, and their close connection with folklore numerical formulas. In this regard, the extreme roughness of specific dates is pointed out, including those contained in the Russian annalistic.

Keywords: chronicles; annals; oral tradition; medieval literature; folklore; Bulgarian apocry-phal chronicle; Tale of Bygone Years; Chronicle of the Priest of Duklja

"Статья подготовлена при финансовой поддержке РФФИ (грант № 17-06-00008А, «Устная историкоэпическая традиция в древнейших памятниках славяноязычной литературы»).

The article was prepared with the financial support of the Russian Foundation for Basic Research (Grant No. 17/06/00008A, «Oral historical-epic tradition in the oldest monuments of Slavonic literature»).
\end{abstract}


Поиски следов устной традиции в памятниках раннего славянского историописания - сами по себе длительная научная традиция, и не менее традиционны споры вокруг нее и самой ее обоснованности. Немалая часть этих споров мотивируется парадоксальным увязыванием вопросов устного происхождения и «достоверности» в «позитивном» ключе. Наследники «исторической» школы минимум до начала 1980-х гг. видели в устном предании гарантию достоверности описываемых событий. Их оппонентов (и в настоящее время) это побуждает к поиску литературных источников для тех же сведений (см.: Алексеев, Плотникова, 2017).

Между тем, выходя за пределы как «историко-мифологических», так и «историко-филологических» дискуссий, нельзя не увидеть очевидных вещей. При наличии у преданий или эпоса исторической основы, эта основа не только не может служить гарантией достоверности, но всякий раз должна становиться предметом тщательной реконструкции. Фольклорное происхождение того или иного мотива часто как раз указывает на его недостоверность с точки зрения формального источниковедения. В то же время фольклорная историческая память сама по себе является историческим фактом. Изучая раннее историописание, мы получаем в свое распоряжение минимум два пласта культурно-исторических представлений. Первым является коллективная «устная» память тех общественных слоев и групп, которые поставляли информацию хронистам и летописцам. Вторым - интерпретация этой информации в рамках новой, письменной и христианской культуры, с использованием ее средств и с ориентацией на ее образцы. При этом четкая грань между первым и вторым размыта или вовсе отсутствует - поскольку в большинстве случаев ранний историк сам является носителем традиции.

В основе сохранения и передачи фольклорной традиции (прежде всего, поэтической), как установлено исследованиями XX в., лежит импровизация на основе устойчивых мотивов, словесных и смысловых «формул». «Формульная» теория была сформулирована А. Б. Лордом в начале 1960-х гг. (Лорд, 1994). С тех пор она успешно применялась при изучении следов устной традиции в различных памятниках древней и средневековой литературы.

К устойчивым составляющим любого фольклорного текста, несомненно, относятся и числовые определители - например, «девять» или «двенадцать» (см.: Лорд, 1994: 102-103, 107, 133, 151, 215). Задолго до «формульной теории» на это обращали внимание самые разные исследователи сказки и эпоса, выделившие ряд «фольклорных» чисел. Типичнее всего число «три» (и кратные), давшее название «Закону трех» - одному из «законов народно-эпического нарратива» датского фольклориста А. Ольрика (Olrik, 1908: 81-83). С. Томпсон в «Указателе мотивов народ- 
ной литературы» выделил целый ряд «формульных чисел» (мотив Z71). K основным им отнесены: $3,4,5,6,7,9,11,12,13,16,30,40,60,72,77$, а также числа типа 101, 1001 и т.п. К «разным»: 8, 10, 14, 15, 17, 21, 22, 25, 26, 32, 53, $56,80,1600,80000,5200000$. Особо отмечаются хронологические числовые формулы (Z72): 7 лет, 3 года, 365 лет, «каждый третий год», «год и день», «7 лет, 7 месяцев и 7 дней», «12 лет и 13 дней» (Thompson, 1957: 553-558).

Как и у всякого ориентированного на формальные признаки подхода в гуманитарных науках, у «формульной» теории есть свои исследовательские «ловушки». На них давно обращено внимание, в том числе и в отечественной литературе. Самое существенное - то, что присутствие той или иной фольклорной по происхождению «формулы» в литературном памятнике не может само по себе означать устного происхождения данной части памятника. Причина очевидна. С момента первого попадания фольклорных «формул» в писаную литературу они начинают воспроизводиться уже в ней независимо от фольклора.

К весьма сложному вопросу об источниках хронологии раннего славянского историописания следует приступать с пониманием вышесказанного. Впрочем, уже для первых исследователей русских летописей было ясно, что безусловное приятие древнейшей летописной хронологии нуждается в обосновании. Романтическому сознанию начала XIX в. в самых разных странах представлялось, что хронологическая информация может свободно передаваться и в устной традиции. Большой энтузиазм в этом смысле придали первые результаты изучения исландских саг, показавшие относительную непротиворечивость их хронологии и совпадения с внешними источниками. Хотя саги были продуктом уже «письменного» общества, но сами они являлись итогом устной традиции. Сделанные на их основе выводы с легкостью экстраполировались на датировки событий бесписьменной эпохи русскими летописцами.

Между тем, уже Н. М. Карамзин, в целом доверявшийся «Повести временных лет», был весьма скептичен в отношении древнейшей летописной хронологии: «Как Нестор мог знать годы происшествий за 200 и более лет до своего времени?.. Нестор по одной догадке, по одному вероятному соображению с известиями византийскими, хронологически расположил начальные происшествия в своей летописи... вероятно ли, чтобы старцы и бояре княжеские, коих рассказы служили, может быть, основанием нашей древнейшей летописи, умели с точностью определить год каждого случая?» (Карамзин, 1988: 31-32).

Эта цитата обоснована, поскольку большая часть сказанного вполне справедлива - и могла бы быть повторена в наше время, потому что вопрос сохраняет актуальность. Отчасти виной сам историограф, который после сказанного, оговорив условности, тем не менее, воспользовался хроноло- 
гией «Повести...» за отсутствием альтернатив. Этой традиции затем почти с той же мотивацией руководствовались поколения отечественных историков, особенно при создании учебных и популярных текстов. Впрочем, в XX в. по социально-культурным причинам немного наивное доверие к летописным датам событий IX-X вв. преобладало и в академической среде. Нередко оно постулировалось без дополнительных обоснований. В других случаях - подкреплялось поисками «дохристианского» (или раннего христианского) летописания на Руси. Вопрос о сомнительности древнейших дат летописи вновь был поставлен в последние десятилетия XX в. Проблеме посвящена и отдельная статья автора этих строк (Алексеев, 2000).

Первое, что следует отметить, говоря о происхождении летописных дат - полное отсутствие следов «глубокой» хронологии в живой славянской традиции. В преданиях иногда отмечаются сроки событий недавних, но по мере удаления от времени рассказчика даже в самых архаичных славянских фольклорных традициях хронологические указания теряются. Нет свидетельств того, что в раннее средневековье было иначе. Нет и достоверных подтверждений того, что было иначе у германцев или, к примеру, кельтов. Связная хронология саг часто недостоверна в деталях. Притом по-настоящему связной она становится в довольно поздней, складывавшейся параллельно с исландской анналистической традицией (на сагах и основывавшейся), версии XIII в. Насколько согласование хронологических выкладок, особенно по ранней истории, являлось следствием усилий исландских эрудитов, судить не всегда можно. В ранних версиях расхождения и между самими сагами (и иными записями устной традиции), и между ними и внешними источниками иногда очень заметны.

Степень глубины «точной» (включая хронологические указания) исторической памяти при бесписьменной передаче информации вообще не следует преувеличивать. Среди славянских культур хороший пример тому дает сербская. С одной стороны, в Сербии и в новое время сохранялись многие черты архаических механизмов воспроизведения и передачи устной традиции. Память «устной истории» могла простираться примерно на пять веков, хотя более раннее время помнилось фрагментарно. Однако наиболее ранние пласты традиции были уже крайне мифологизированы, и историческая реальность в них размывалась. Так же было и на более ранних этапах развития самой традиции. В XIV в., когда создавался письменный «Родослов», его составителям в совершенно искаженном виде представлялись реалии XI-XII вв., и достоверной генеалогия становилась только с середины XII в. Стоит заметить, что и до, и после этого рубежа составитель «Родослова» явно предпочитал его устные прообразы письменным источникам. Поэтому и в «исторической» части есть грубые ошибки (см.: Алексеев, 2017: 57-60, 380-381). 
Итак, на рубеже дописьменной и раннеписьменной эпохи славяне располагали, скорее всего, устной исторической традицией о событиях нескольких ближайших веков со сравнительно неглубокой и случайной хронологией. Едва ли «помнились» относительные даты и сроки событий (все равно условные, сохраняемые лишь личной памятью носителей традиции) далее чем века. Хронология для архаического общества непринципиально сама по себе - в историко-генеалогической традиции единицей времени является не год, а поколение.

Это подтверждает самая ранняя «запись» славянской исторической традиции - «сербская» глава трактата Константина Багрянородного «Об управлении Империей». Здесь указаны сроки правления князей последних двух поколений, но не более ранних, а история более чем столетней давности сводится к этногонической легенде и перечню поколений (Константин ..., 1991: 140-149).

Исходное состояние хронологии славянских традиций неплохо фиксируется и русским агиографом XI века (скорее первой половины) Иаковом Мнихом. Он приводит три точные даты по византийскому летоисчислению: смерть Ольги, вокняжение и смерть Владимира. Они, вероятно, были так и зафиксированы киевскими христианами. Отталкиваясь от них, он датирует события времен Владимира до крещения по годам правления (что скорее традиционный для собственной культуры способ). Есть также относительная датировка крещения Ольги, отсчитанная от ее смерти, за 15 лет (см.: Милютенко, 2008: 425-426, 499-500). Эта явно округленная «дата» затем переходит и в летописи, дополнившись другой, видимо, еще более условной - 10 лет от вокняжения до крещения. Иакову последняя «дата» еще неизвестна.

То же мы видим и в первых латиноязычных хрониках славянских государств. Ни «Деяния князей польских» Анонима Галла, ни «Чешская хроника» Козьмы Пражского не дают ни абсолютных, ни относительных дат языческой истории. Нет и сроков правления князей дописьменной эпохи. «Хроника» Козьмы построена по анналистическому принципу, однако датировки событий начинаются только с конца IX в. При этом первая же дата (894 г.) ошибочна, являясь попыткой согласовать хронологию немецкого хрониста Регинона с чешскими преданиями (см.: Козьма ..., 2009: 62-63).

Встреча первых славянских книжников с хронологией Библии и византийских хроник стала серьезным культурным «вызовом» (если не культурным шоком). Иоанн Малала, Георгий Амартол, Георгий Синкелл лишь теоретически понятным для первых ученых славян способом «помнили» сроки правлений и даты событий на сотни и тысячи лет назад. Библия же давала славянам точную, и притом сочетаемую с привычным 
историко-родословным принципом хронологию от самого сотворения мира. Структура типа библейских родословных была знакома в любой точке христианизируемого «варварского» мира. Но сопровождение их на всем протяжении точными (пусть сначала невероятно большими для нынешнего времени) сроками жизни персонажей, затем правлений царей - было внове. Создающий историю своего народа и государства средневековый книжник не мог в итоге не принять «вызов» и не начать искать пути его решения.

Основных путей было два. Первый - подражание имевшимся образцам. Само по себе это подразумевало вымысел, даже определенный «подлог», едва ли приемлемый для всех авторов древнейших исторических сочинений. Вместе с тем, здесь могли вступать в силу механизмы «уподобления» собственной и библейской истории, поисков в первой промыслительного измерения, которое должно было проявляться в «повторении» второй. Действие этих механизмов рассматривалось на разных примерах, в том числе летописной истории Владимира Святого (Плотникова, 2015: 45-63). Вторым путем являлось использование фольклорных «дат». По мере удаления от реально «помнившегося» времени временные указания не исчезали вовсе, но принимали обобщенно-эпический характер. Для русских былин и сказок характерен срок-формула «тридцать лет и три года» - на котором сейчас ни один историк не будет строить хронологию. Но такого рода «даты» могли использоваться первыми историками славянского мира для восполнения обнаруженного ими культурного недостатка. Оба пути с легкостью могли пересекаться. Например, хорошо известный в фольклоре разных народов срок в 40 лет не раз встречается и в Библии.

В древнейшем (при датировке 1070-ми гг.) памятнике славяноязычного историописания - русском Начальном своде - проблема стояла не слишком остро. Рюриковичи были относительно молодой династией. Начальный летописец, использовавший традицию, родственную «Памяти и похвале» Иакова Мниха, ограничился малым. Он разбил свое повествование об Ольге, Святославе и Владимире на отдельные сюжеты, сгруппировав их в погодные статьи (что чувствуется по неверным датировкам походов Святослава). Автор отсчитал 10 лет вглубь от «даты» крещения Ольги по Иакову и расставил от получившейся статьи 945 г. первые сюжеты ее правления. Более ранний период он фактически не датировал никак. Дата 6362 (854) г. для «Начала Русской земли», под которой сгруппированы предания о первых князьях от Кия до Игоря (Полное собрание ... , 2000: 104-107), условна. Вероятнее всего, летописец отсчитал 200 лет от даты смерти Ярослава Мудрого, исходя из того, что династия существует примерно два века. Это могло иметь основания в родовом предании, но и быть конструкцией самого автора. 
Вместе с тем, влияние фольклорной «хронологии» уже в этой летописи чувствуется и более явно. Неудачный поход Игоря на Византию, описанный по греческому источнику, ошибочно датирован 920 г. (вместо 941) - первым годом правления упоминаемого в связи с ним императора Романа. Однако далее идет неизвестный византийским историкам и успешный поход (в «Повести временных лет» раздвоившийся на походы 907 и 944 гг.). Он датируется «на третий год» после первого - 922 г. Та же схема далее используется при датировке приобретений воеводы Свенельда. Получение им деревской дани (приведшее к гибели Игоря, по летописи, в 945 г.), датировано за три года до 945-го. Само же это приобретение происходит через два года на третий после покорения Свенельдом угличей (там же: 108-111).

Во многих смыслах антиподом русского летописца являлся автор т.н. «Болгарской апокрифической летописи» (ок. 1091 г.?). Она уникальна тем, что представляет почти фольклорный взгляд на историю, усложненный религиозными представлениями богомильства, но не книжной историографией. В ней мы находим архаические мифы, топонимические предания, различные версии представлений об одних и тех же персонажах. Иногда автор подставляет вымышленные имена «библейского» типа, заполняя естественные лакуны компилируемых им разрозненных фольклорных сюжетов. Возможны абсурдные казусы вроде отождествления Константина Великого и Константина Багрянородного (немногим более века спустя после смерти последнего).

Одна из характерных черт «Летописи» - фантастические сроки правления всех до единого упоминаемых болгарских и византийских «царей» (см.: Тъпкова-Заимова, Милтенова, 1996: 195-198). Даже вполне реалистичные на самом деле фиктивны. «Летописец» подражал библейской хронологии - что заметно по долгим правлениям первых «царей», достойным библейских патриархов. Некоторые сроки взяты - быть может, и невольно, - из Писания и апокрифов, либо просто выдуманы. Но и воздействие фольклорного «хронологического» мышления очевидно. Срок правления «Испора» (хана Аспаруха) - 172 года (100+72), следующего выдуманного «царя Изота» - «100 лет и 3 месяца», Симеона - 130 лет. Другая версия Симеона царствует 12 лет, как и царь Петр; Роман - 9 лет; легендарная «вдовица» - 3 года. Выдуманный царь Селевкия и несостоявшийся претендент на престол Августиан (исторический Алусиан) «царствуют» по 37 лет. Ареву, заговорщику, в ожидании воцарения которого создавалась «Летопись», предсказано правление в фольклорные 7 лет. Отсюда видно, что даты выдуманы «летописцем», а не брались из какоголибо предания, - но выдуманы они носителем той же традиции, мыслившим так же, как народный сказитель. 
Нечто подобное, видимо, имело место во второй половине XII в. при создании славяноязычного прототипа другого южнославянского исторического сочинения - латинской «Летописи попа Дуклянина». Она гораздо «строже», отражая династическую традицию Дуклянской державы. Вместе с тем хронология правлений до начала XI в., а отчасти и позднее, не менее искусственна. От прихода славян на Балканы до прихода болгар в «Летописи» проходят 33 года, разложенные на два княжеских правления -21 и 12 лет. 12-летний срок правления повторяется несколько раз в разных формах: «в 12-й год» умирает Светолик; «в 13-й год»- король Томислав; 24 года (12 по 2) правит следующий король Себеслав. «40 лет и 4 месяца» правит король-креститель Святополк. Срок правления короля Крепимира (25 лет) совпадает с предполагаемым сроком его прототипа хорватского князя Трпимира І. Но не исключено, что это совпадение случайно. Столько же правит уже в XI в. основатель Дуклянской державы Доброслав (исторический Воислав). При этом сроки правления и его, и его сына Михайлы (35 лет) с трудом согласовываются с данными византийских источников (см.: Алексеев, 2015).

Похожий подход мы обнаруживаем и в «Повести временных лет» при датировке событий языческой эпохи (см.: Полное собрание ..., 1997: 18-60). Перед Нестором стояла более сложная задача. Даже отказавшись датировать события ранее середины IX в. (как и Козьма Пражский), русский летописец тем не менее постарался точно определить даты всех событий с этого времени. Часть опорных точек обеспечили ему русско-византийские договора (907, 911/2, 944/5, 971 гг.) и известия византийских хронистов $(866,941$ гг.). Но в остальных случаях можно было опираться только на сроки правлений князей, отсчитывая от них условные «даты» по образцу Начального летописца. В верности показаний последнего после 945 г. Нестор убедился благодаря совпадению дат договора Святослава и его летописного похода в Болгарию. Кроме того, договор Игоря (944/5 г.) подходил к летописной дате его смерти. Но далее предшественник явно ошибался: поход Игоря имел место не в 920, а в 941 г., и легендарный поход-реванш следовало отнести к 944-му. Помимо того, в 907-912 гг. великим князем, как узнал Нестор из договоров, был Олег.

Оставалось положиться на традицию (или, точнее, интерпретировать ее в соответствии со своими обновленными представлениями). То, что между договором Олега и договором Игоря прошло действительно 33 года, обеспечило этому «фольклорному» сроку доверие летописца. В итоге и Олег (879-912), и Игорь (912-945) правят в «Повести» каждый по 33 года. Из какой-то легенды наподобие отразившихся в Проложном житии (Лосева, 2009: 423) исходит датировка женитьбы Игоря на Ольге 903 г. Достойно замечания, что это за 9 лет до смерти «приведшего» Ольгу Оле- 
га. Что касается внешне достоверного срока правления Рюрика (17 лет, 862-879), то при ближайшем рассмотрении выясняется, что он исходит из той же «троичной» арифметики. Аскольд и Дир совершают поход на Византию в 866 г. - через два года на третий после своего утверждения в Киеве, вскоре по смерти братьев Рюрика. Братья Рюрика умирают через два года на третий после призвания. Таким образом, призвание варягов надо было отнести к 862 г., а брали варяги дань до этого дань с северных племен 3 года (859-862).

Таким образом, условность даже обычно принимаемой на веру в науке ранней летописной хронологии более чем заметна. Собственно говоря, в случае с былинными «33-мя годами» Олега и Игоря даже об условности говорить не очень уместно. Значит ли это, что на известия ранних памятников славянского историописания о дописьменной и раннеписьменной эпохе не следует полагаться вовсе? Думается, что нет. Устная историческая память не состоит из одних фикций и условностей. Условность дат не есть недостоверность фактов и особенно ключевых для сохранения традиции генеалогий. Но осознание этой условности необходимо для объективного - и осторожного - научного подхода.

\section{СПИСОК ЛИТЕРАТУРЫ}

Алексеев, С. В. (2000) Древнейшая летописная хронология // Историческое обозрение. Вып. 1. М. : ИПО. С. 5-13.

Алексеев, С. В. (2015) Летопись попа Дуклянина. СПб. : Петербургское востоковедение. 288 с.

Алексеев, С. В. (2017) Памятники сербской средневековой историографии XIII-XVII вв. Переводы и исследование. Летописи. СПб. : Петербургское востоковедение. Т. 2. Жития XIV-XVII вв. Родословы. 464 с.

Алексеев, С. В., Плотникова, О. А. (2017) Отражение эпоса и преданий в древнейших памятниках славяноязычной литературы: к методологии выявления // Знание. Понимание. Умение. № 3. С. 226-235. DOI: 10.17805/ zpu.2017.3.17

Карамзин, Н. М. (1988) История государства Российского. М. : Книга. T. $1.701 \mathrm{c}$.

Константин Багрянородный (1991). Об управлении Империей. М.: Наука. 496 с.

Козьма Пражский (2009). Чешская хроника. Аноним Галл. Хроника и деяния князей, или правителей польских. Рязань : Александрия. 416 с.

Лорд, А. Б. (1994) Сказитель. М. : Восточная литература. 368 с.

Лосева, О. В. (2009) Жития русских святых в составе древнерусских Прологов XII - первой трети XV веков. М. : Рукописные памятники Древней Руси. 472 с. 
Милютенко, Н. И. (2008) Святой равноапостольный князь Владимир и крещение Руси. Древнейшие письменные источники. СПб. : Издательство Олега Абышко. 576 с.

Плотникова, О. А. (2015) Рождение русской словесности. М.: Вече. 288 с.

Полное собрание русских летописей (1997). М. : Языки русской культуры. Т. 1. Лаврентьевская летопись. 496 с.

Полное собрание русских летописей (2000). М. : Языки русской культуры. Т. 3. Новгородская первая летопись старшего и младшего изводов. 720 c.

Тъпкова-Заимова, В., Милтенова, А. (1996) Историко-апокалиптичната книжнина във Византия и в средновековна България. София: Университетско издателство «Св. Климент Охридски». 360 с.

Olrik, A. (1908) Episke love i folkedigtningen // Danske Studier. 8. S. 69-89.

Thompson, S. (1957) Motif-index of folk-literature. Vol. 5. Bloomington: Indiana University Press. 568 p.

Дата поступления: 12.10.2017 2.

Алексеев Сергей Викторович - доктор исторических наук, профессор, председатель Историко-просветительского общества «Радетель», директор по научным вопросам Фонда «Связь эпох». Адрес: 123098, Россия, г. Москва, ул. Маршала Василевского, д. 9, к. 5 . Тел.: +7 (499) 190-52-65. Эл. адрес: ipo1972@mail.ru

Alekseev Sergey Viktorovich, Doctor of History, Professor, Chairman, the Historical and Educational Society «Radetel», Director for Scientific Affairs, the Foundation "Link of Epochs". Postal address: 9, Bld. 9, Marshala Vasilevskogo St., Moscow, Russian Federation 123098. Tel.: +7 (499) 190-52-65. E-mail: ipo1972@mail.ru

\section{Для цитирования:}

Алексеев С. В. «Тридцать лет и три года»: о хронологии раннего славянского историописания [Электронный ресурс] // Научные труды Московского гуманитарного университета. 2017. № 6. URL: http://journals.mosgu.ru/trudy/article/view/621 (дата обращения: дд.мм.гг.). DOI: 10.17805/trudy.2017.6.5 